\title{
Disfunção craniocervicomandibular com sintomatologia vestibulococlear: relato de caso
}

\author{
Craniocervicomandibular disfuccion with vestibulococlear symptomatology: case report \\ Disfunción craniocervicomandibular com sintomatologia vestibulococlear: reporte de caso \\ Lohanna Karoline Rodrigues ROSSETE \\ Aréli Morais de Araújo ALENCAR \\ Myrian Salles VIEIRA \\ Lioney Nobre CABRAL
}

Escola Superior de Ciências da Saúde, Universidade do Estado do Amazonas (ESA-UEA), 69065-001 Cachoeirinha, Manaus - AM, Brasil

\begin{abstract}
Resumo
A disfunção craniocervicomandibular envolve um conjunto de estruturas, incluindo a articulação temporomandibular, músculos da mastigação e do pescoço. As alterações vestibulococleares estão intimamente ligadas às disfunções musculares cervicais e mastigatórias por conta das proximidades anatômicas e sua fisiologia. Além delas, nesses casos também há presença de dores referidas (faciais, otalgias, cefaleias, periorbitais, etc), ruídos articulares, alterações da dinâmica mandibular, desvios, deflexões e restrição dos movimentos. Este trabalho apresentará um caso em paciente de 39 anos de idade, sexo feminino, com queixa de dores de cabeça, orelha, por trás dos olhos, zumbidos, estalidos articulares, deslocamento mandibular além de tontura/vertigem. Realizados anamnese, exames físicos e complementares, o diagnóstico foi de disfunção craniocervicomandibular com sintomatologia vestibulococlear, seguido do tratamento proposto, o qual consistiu em exercícios de fisioterapia e uso de dispositivo interoclusal, apresentando efetividade, com resolução do quadro doloroso, otológico e vestibular.
\end{abstract}

Descritores: Transtornos da Articulação Temporomandibular; Otalgia; Vertigem.

\section{Abstract}

Craniocervicomandibular dysfunction involves a set of structures, including the temporomandibular joint, masticatory and neck muscles. Vestibulocochlear alterations are closely linked to cervical and masticatory muscle dysfunctions due to anatomical proximity and their physiology. In addition to these, in these cases there is also the presence of referred pains (facial, otalgias, headaches, periorbitals, etc.), joint noises, changes in mandibular dynamics, deviations, deflections and movement restriction. This work will present a case in a 39-year-old female patient, complaining of headaches, ear, behind the eyes, tinnitus, joint clicks, mandibular dislocation in addition to dizziness / vertigo. Anamnesis, physical and complementary exams were performed, the diagnosis was craniocervicomandibular dysfunction with vestibulocochlear symptoms, followed by the proposed treatment, which consisted of physiotherapy exercises and use of an interocclusal device, showing effectiveness, with resolution of the painful, otological and vestibular condition.

Descriptors: Temporomandibular Joint Disorders; Earache; Vertigo.

\section{Resumen}

La disfunción craneocervicomandibular implica um conjunto de estructuras, que incluyen la articulación temporomandibular, los músculos masticatorios y del cuello. Las alteraciones vestibulococleares están estrechamente relacionadas com las disfunciones musculares cervicales y masticatorias debido a la proximidade anatómica y su fisiologia. Además de estos, em estos casos también existe la presencia de Dolores referidos (faciales, otalgias, Dolores de cabeza, periorbitales, etc.), ruídos articulares, cambios em la dinâmica mandibular, desviaciones y restricción de movimento. Este trabajo presentará um caso en una paciente de 39 años, que se queja de Dolores de cabeza, oídos, detrás de los ojos, tinnitus, chasquidos articulares, deslocamiento mandibular, además de mareos/vértigo. Se realizaron exámenes de anamnesis, físicos y complementários, el diagnóstico fue disfunción craneocervicomandibular com sintomas vestibulococleares, seguido del tratamento propuesto, que consistió em ejercicios de fisioterapia y el uso de um dispositivo interoclusal, mostrando efectividad, com resolución de la condición dolorosa, otológica y vestibular.

Descriptores: Trastornos de la Articulación Temporomandibular; Dolor de Oído; Vértigo.

INTRODUÇÃo

As disfunções craniocervicomandibulares envolvem uma união de fatores que afetam não apenas as articulações temporomandibulares (ATM), mas também estruturas a ela associadas. Dor, cefaleias, ruídos articulares, alterações da dinâmica mandibular, desvios e deflexões, restrição dos movimentos e alterações do tônus muscular, que podem comprometer regiões da cabeça e pescoço: temporais, occipitais, frontais, cervicais, préauriculares, auriculares e orbitais. Muitos pacientes queixam-se de sintomas otológicos e vestibulares associados à dor e disfunção das ATMs, sendo elas: otalgia, zumbido, plenitude auricular, tontura ou vertigem e perda auditiva. Isso se explica fisiologica e anatomicamente, visto que a origem dos ossículos da orelha média e mandíbula se originam do mesmo arco braquial, anatomicamente, suas estruturas estão bem próximas e, além disso, há interrelação neuromuscular da ATM, orelha média e o músculo pterigoideo medial que interfere na função do tensor do véu palatino, ambos inervados pela parte motora do $\mathrm{V}$ par craniano. Outras dores também podem ser sintomas, justificadas a partir de pontos-gatilho presentes nos músculos mastigatórios e cervicais e suas referências possíveis, como a ocorrente na região periorbital e odontalgias de origem não odontogênicas. As condições musculoesqueléticas originadas nos músculos da mastigação ou do pescoço são as maiores causas de dores referidas ${ }^{1-3}$.

$$
\text { A dor, disestesia ou alteração }
$$

autonômica podem ser geradas por alta contração e/ou estiramento dos músculos, que levam à hipertonia de um adjacente, sendo a condição muitas vezes referida em uma região 
diferente e distante do local de origem, isso porque o caminho nociceptivo de condução de neurônios primários e as possibilidades sinápticas de vários destes em um único secundário, no Sistema de Núcleos trigeminais, na ponte do mesencéfalo, podem distinguir a origem do local da dor, caracterizando a dor heterotópica ou referida ${ }^{4-6}$.

O conjunto de fatores como traumas, hábitos parafuncionais, mudanças nas posições funcionais da cabeça e coluna cervical, resultam em alterações levando à disfunção craniocervicomandibular (DCCM), dores faciais, dores de cabeça e desequilíbrios posturais. A perda postural subjacente à influência direta na posição do movimento da mandíbula, associada a uma disfunção cervical, funciona como um fator etiológico para desenvolver as disfunções craniocervicomandibulares. A articulação temporomandibular é uma das estruturas que compõe o Sistema Estomatognático. Além dela, é composto pelos ossos do crânio: frontal e temporal, do pescoço: hióide e vértebras cervicais, da face: maxilar, do tórax: esterno e clavícula, além de dentes e estruturas que os rodeiam e servem de suporte, sistema sanguíneo, linfático, nervoso, muscular, entre outros elementos ${ }^{1,2}$.

Existe um trígono de sustentação que a ATM faz com vértebras do pescoço, chamado de sistema manducatório, o qual interfere no equilíbrio da coluna cervical, assim, podendo prejudicar diversas funções orgânicas. As alterações ao longo das cadeias biomecânicas podem ser resultado das relações anormais entre a coluna cervical e o complexo craniocervicomandibular. As mudanças da postura da cabeça e da coluna cervical afetam a posição da mandíbula. Isso mostra a influência da postura nos distúrbios temporomandibulares e cervicais. Nas observações clínicas uma postura anterior da cabeça está relacionada com distúrbios craniocervicomandibulares (DCCM). Na postura anterior da cabeça, esta encontra-se deslocada para frente sobre a região cervical estendida e sobre uma coluna cervical inferior flexionada. Pacientes portadores de sinais e sintomas de DTM apresentam uma posição mais anterior da cabeça e ombros mais protruídos, de forma mais relevante que em pacientes não-portadores desses sinais e sintomas. Uma posição anterior da cabeça pode causar disfunção da coluna cervical, além de mudar a conformação muscular ao redor, podendo provocar dor ${ }^{1,2,7}$.

Os deslocamentos de disco da ATM são considerados uma importante causa da dor facial, de estalidos, crepitação e disfunção. Os deslocamentos de disco com redução estão frequentemente associados a estalidos, e os deslocamentos de disco sem redução apresentam-se mais frequentemente associados à limitação da abertura de boca. Além do deslocamento provocado pela ausência de redução do disco, existe o deslocamento provocado pela tensão da musculatura da mastigação, que faz com que a mandíbula se desloque para o lado descompensado em movimentos de abertura bucal. Características clínicas que podem nos sugerir que tenha redução ou não do disco, é de extrema necessidade uma ressonância magnética para o fechamento diagnóstico e montagem do plano de tratamento. Excluindo estes, os sinais e sintomas são advindos da disfunção muscular ${ }^{8}$.

Além disso, acredita-se que numa proporção de 5 pra 1 , há uma prevalência em mulheres e muitos autores citam essa situação. Essa desproporção entre homens e mulheres sugere que há ativação diferenciada no sistema de analgesia endógena e no processamento de estímulos nociceptivos. Estudos com neuroimagem mostraram a ativação de áreas corticais e subcorticais comuns em homens e mulheres, áreas que estão ligadas a espaço gênero-especifica em resposta cerebral a estímulos dolorosos. Nos homens houve grande ativação das áreas cognitivas e simpática central, e inibição da região límbica. Nas mulheres teve a ativação do sistema límbico e regiões autonômicas, locais não ativados geralmente nos homens ${ }^{4-6,9}$. Conjetura-se assim, a importância do sistema límbico e do eixo hipotálamo-hipófise-adrenal, nesta condição mais comum no sexo feminino e, além disso, a predominância, nas mulheres, de fibras musculares do tipo I, que não resistem a um tempo tão longo de anaerobiose, diferentes dos homens, que apresentam células do tipo II que suportam uma anaerobiose mais longa.

Por ser uma condição complexa e de difícil diagnóstico, é de extrema importância que o profissional faça uma boa anamnese, exame físico, palpação da musculatura tanto mastigatória quanto cervical, conheça a condição, como ela ocorre, e suas variações com diferentes diagnósticos e tratamentos. Os tratamentos de escolha são multidisciplinares e clínicos, tendo como objetivo o equilíbrio dinâmico e postural do organismo do paciente. Dentre eles estão: fisioterapia, uso da placa interoclusal com funcionalidade neuromuscular, laserterapia, psicologia no tratamento cognitivocomportamental, entre outros. $E$ dos casos com envolvimento articular, apenas $5 \%$ são tratados cirurgicamente $e^{1,2,10}$. 


\section{CASO CLÍNICO}

O presente estudo relata o caso em paciente, sexo feminino, 39 anos, com queixa de dores de cabeça, orelha, por trás dos olhos, zumbidos, estalidos articulares, deslocamento mandibular além de tontura/vertigem. Relatou que há mais ou menos 2 anos, acontece o deslocamento da mandíbula. Mas há 1 ano, começou a sentir fortes dores de cabeça, tonturas, sensação de ouvidos tampados (plenitude auricular), zumbidos, dor bilateral na ATM (com intensidade maior do lado esquerdo), estalidos e crepitações, pontadas no peito e dores por trás dos olhos. Começou-se então a avaliação das desordens temporomandibulares, onde relatou apertamento dos dentes durante 0 dia, principalmente quando estava distraída (bruxismo em vigília) e durante a noite (bruxismo noturno). Nas mensurações, paciente possuía movimentos limitados, principalmente em abertura bucal, medindo $33 \mathrm{~mm}$, abaixo dos padrões de normalidade (Figura 1), e ainda apresentava deflexão para a esquerda (Figura 2 ), seu lado mais acometido. Além de uma acentuada assimetria postural (Figura 3), anteriorização da cabeça e protrusão de ombros, percebidos mais pelo lado esquerdo (Figura 4) do que do direito (Figura 5), devido toda a conjuntura muscular do lado esquerdo ser mais comprometida.

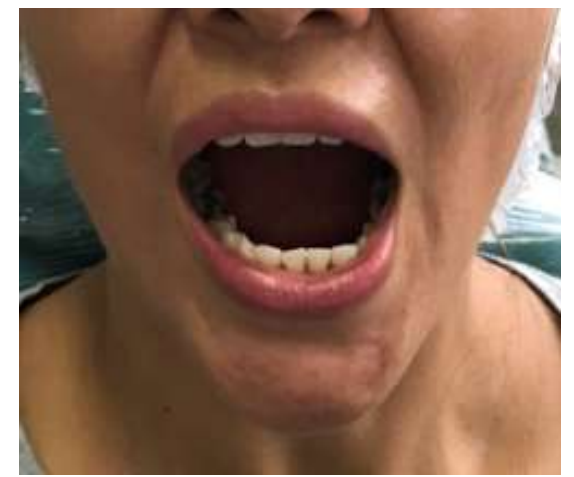

Figura 1: Abertura bucal limitada com desvio para esquerda.

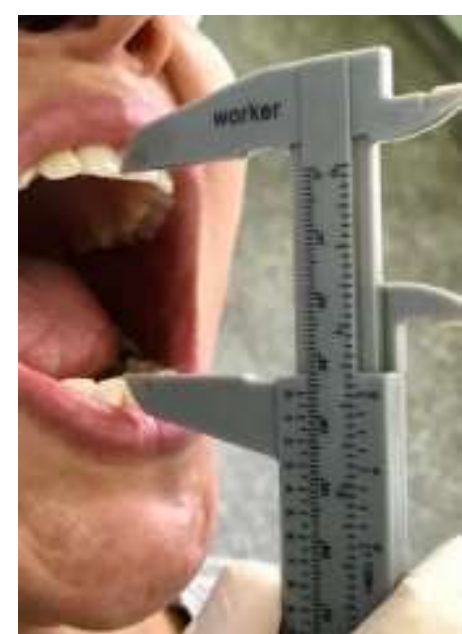

Figura 2: Abertura bucal inicial, com 33mm.

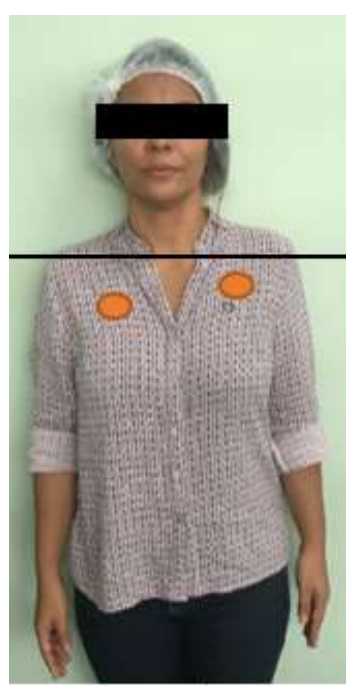

$\begin{aligned} & \text { Figura 3: Assimetria } \\ & \text { postural. }\end{aligned}$

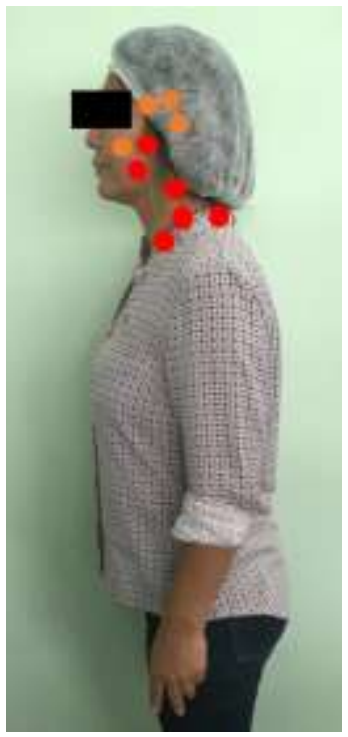

Figura 4: Perfil esquerdo inicial.

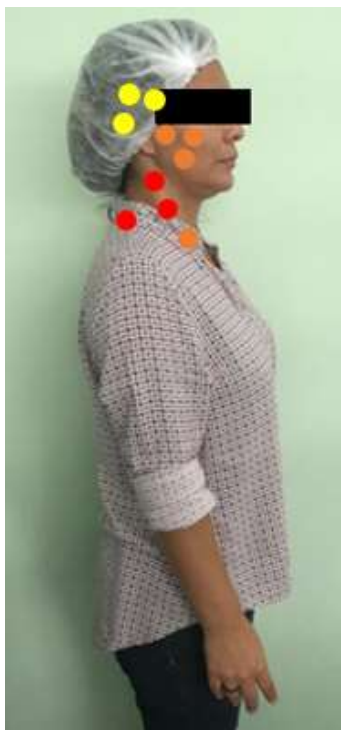

Figura 5: Perfil direito inicial.

Tais limitações, dores, e assimetria postural, explicadas pelo comprometimento dos músculos mastigatórios e cervicais, principalmente os elevadores da mandíbula (masseter, pterigoideo medial e temporal), os cervicais (trapézio descendente, esternocleidomastóideo e grupos musculares do 
trígono sub-occipital) medidos de acordo com o exame de palpação da musculatura, sendo designados por níveis de dor (Tabela 1).

\begin{tabular}{l|l}
\multicolumn{2}{c}{ Tabela 1: Níveis de dor } \\
\hline Cor & Nível de dor \\
\hline Azul & Ausência de dor \\
\hline Amarelo & Dolorimento \\
\hline Laranja & Dor \\
\hline Vermelho & Reação de fuga \\
\hline
\end{tabular}

Esse comprometimento explica a cefaleia, os estalidos e crepitações da articulação temporomandibular, o deslocamento da mandíbula para o lado esquerdo, as dores retro-orbital e peitoral, plenitude auricular e zumbidos. Enquanto eram feitas as palpações da musculatura, paciente relatou dor de cabeça e dor na orelha, então foi realizada infusão de lidocaína $2 \%$ em músculos trapézio descendente e corpo de esternocleidomastoideo (Figura 6) a fim de relaxar esses pontos hipersensíveis e, com isso, observou-se que as dores que a paciente relatou cessaram-se. Logo, deu-se o diagnóstico de disfunção craniocervicomandibular com sintomatologia vestibulococlear e possível deslocamento mandibular sem recaptura do disco, dando-se início aos passos para confecção da placa miorrelaxante (Figura 7).
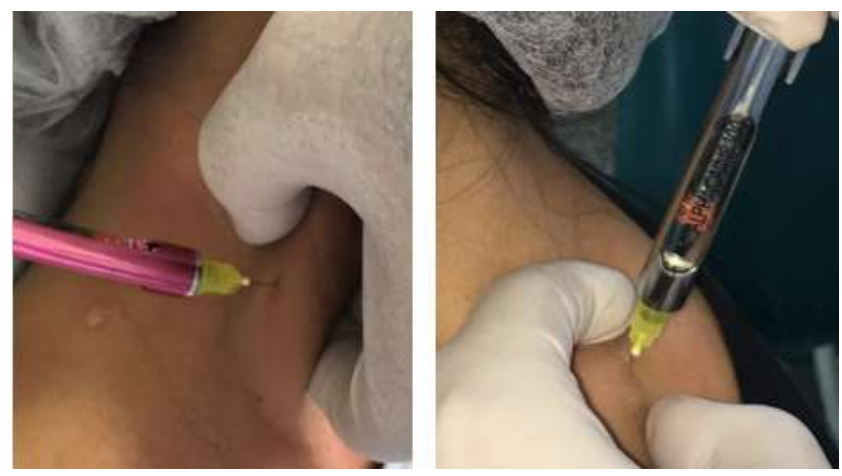

Figura 6: Infusão de lidocaína 2\%.
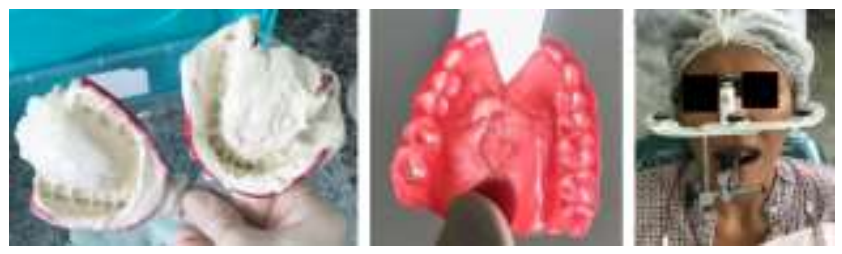

Figura 7: Passos para confecção da placa miorrelaxante.

Foi realizado a moldagem com alginato dos arcos superiores e inferiores, posterior vazamento com gesso tipo IV para confecção de modelo de trabalho, registro de mordida em cera, montagem do arco facial para montagem em articulador semi-ajustável e encaminhados ao laboratório. Depois de uma semana, a placa miorrelaxante foi instalada, feitos os ajustes e entregue à paciente (Figura 8) para fazer uso diariamente, 1 a 2 horas depois dos exercícios da manhã e da tarde, e depois do exercício da noite, dormir com ela. Os exercícios de fisioterapia (Figura 9) associados ao uso da placa e à termoterapia prescritos à paciente consistiam em 1: abertura mínima de boca contra uma resistência, colocando entre as mãos e o rosto compressa morna úmida ou fria, dependendo do clima, mantendo durante 10 segundos e repetindo 10 vezes, 3 vezes ao dia, manhã, tarde e noite.

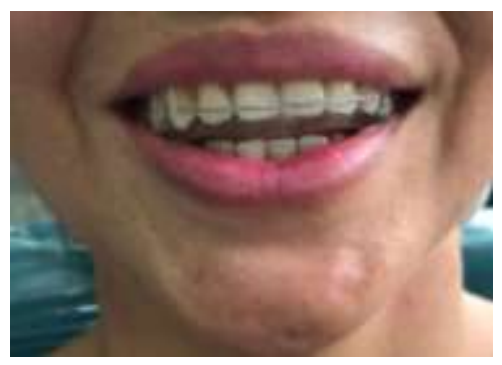

Figura 8: Placa miorrelaxante instalada.

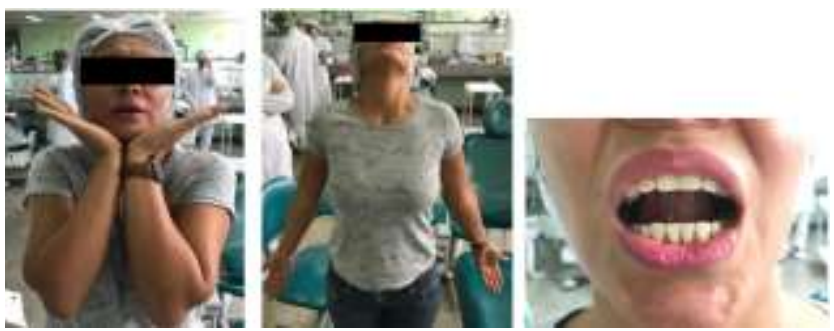

Figura 9: Exercícios de fisioterapia iniciais, 1, 2 e 3.

Em seguida, 2: uma vara de cerca de 50 cm entreposta entre os antebraços e a região lombar, com as mãos em palma, para a reorientação da cintura escapular e redução da protrusão de ombros com inspirações regulares inclinando a cabeça para trás e retomada à posição original da cabeça expirando pela boca (com o fim de recondicionar os músculos esternocleidomastóideos bilateralmente), por 5 a 10 minutos, após o primeiro exercício, e por último, 3: a colocação da língua no palato com abertura de boca máxima possível sem desconforto, mantendo durante 10 segundos, 3 repetições. Realizada proservações semanais, com intuito de acompanhar a adaptação da paciente com 0 tratamento. Em consultas posteriores, em 1 semana, já tivemos resultados positivos do tratamento, a paciente já não relatava dores, apenas ainda ouvia zumbidos, estalidos e apresentava deflexão na abertura bucal, sendo incluído em razão desta permanência, um quarto exercício fisioterápico: abertura e fechamento da boca orientados com o dedo indicador e polegar e compressa local conforme prescrição primária (Figura 10), com o fim de trabalhar a orientação de abertura e fechamento bucal em linha média. Além disso, eram realizados os ajustes do dispositivo interoclusal por meio da checagem dos contatos com carbono e pinça miller, ajustada com micromotor, peça reta e broca maxicut (Figura 11), para que, na reorganização da 
musculatura, nós avaliássemos as mudanças dos contatos e ajustássemos, e que com isso, pudéssemos ter o máximo de contato na placa para conseguirmos a estabilidade neuromuscular e a devolução da propriocepção muscular. Algumas infusões de lidocaína 2\% foram realizadas em região de músculo masseter, em trapézio descendente e em pterigoideo medial (Figura 12) para relaxar instantaneamente os pontos-gatilho, potencializar a efetividade da fisioterapia, propiciar a abertura bucal em linha média e também para fecharmos o diagnóstico.

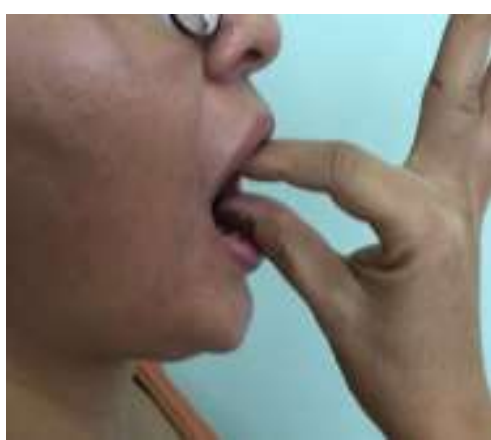

Figura 10: Exercício de fisioterapia, 4.

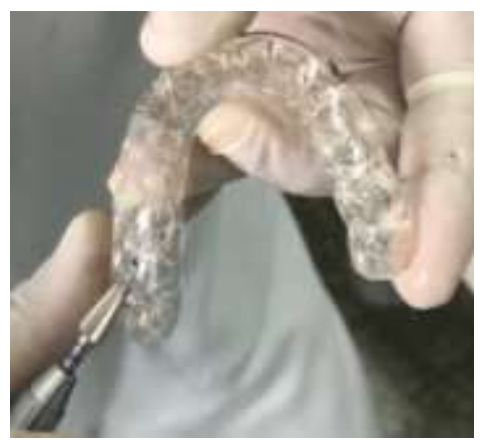

Figura 11: Ajuste da placa.
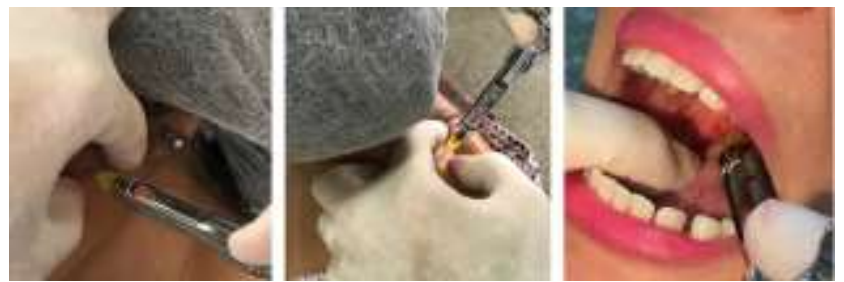

Figura 12: Infusão de lidocaína $2 \%$.

Após 8 meses de proservação, paciente mostrou melhora do quadro. Ausência de dores, tanto do lado esquerdo (Figura 13), quanto do direito (Figura 14), assimetria postural praticamente nula (Figura 15), com leve desvio e retorno a linha média, deixando de existir a deflexão inicialà esquerda com limitação de abertura. Visto que, com o tratamento, a paciente conseguiu melhorar a reorientação da abertura bucal, descartamos a possibilidade do envolvimento do disco articular nesse caso, confirmado em ressonância magnética (Figura 16) sendo 0 deslocamento mandibular potencialmente causado pela disfunção muscular, sendo o diagnóstico final de disfunção craniocervicomandibular com sintomatologia vestibulococlear. Manteve-se 0 tratamento prévio, com retornos para avaliações mensais e foi visto que a estabilidade no dispositivo interoclusal continuou mantido (Figura 17), as dores não retornaram, e a abertura bucal chegou à linha média (Figura 18), além da abertura bucal da paciente ter aumentado $13 \mathrm{~mm}$ (de $33 \mathrm{~mm}$ para $46 \mathrm{~mm}$ ) desde o início do tratamento (Figura 19).

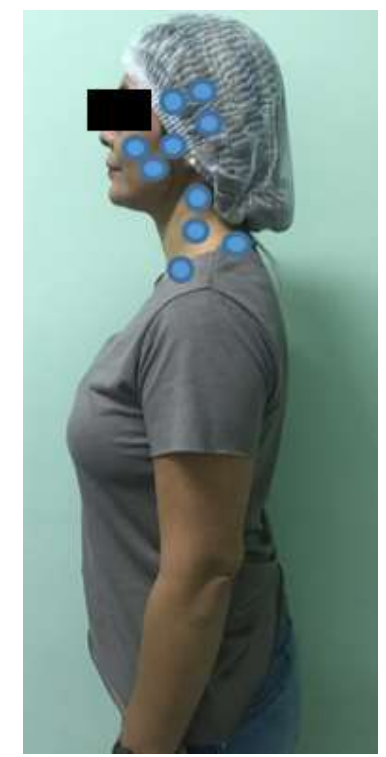

Figura 13: Perfil esquerdo

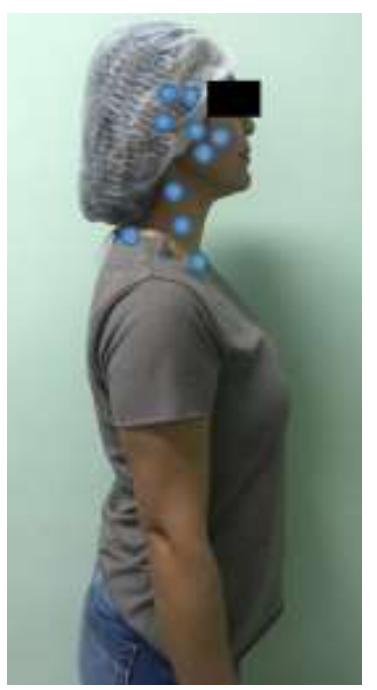

Figura 14: Perfil direito

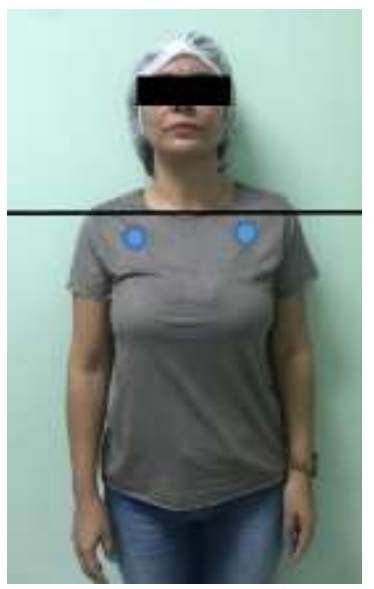

Figura 15: Assimetria postural praticamente nula 


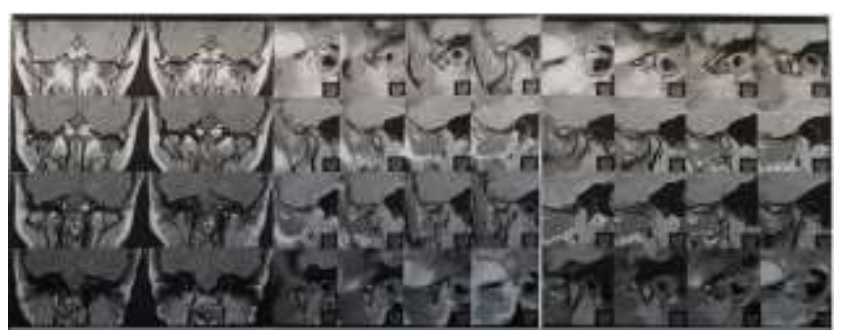

Figura 16: Ressonância magnética do disco articular.

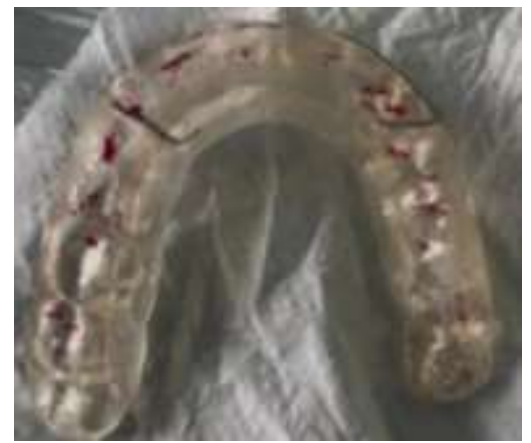

Figura 17: Manutenção da estabilidade do dispositivo interoclusal.

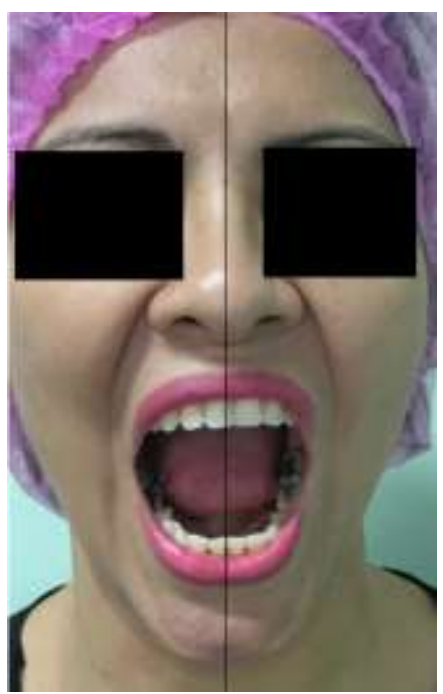

Figura 18: Abertura bucal final com retorno à linha média.

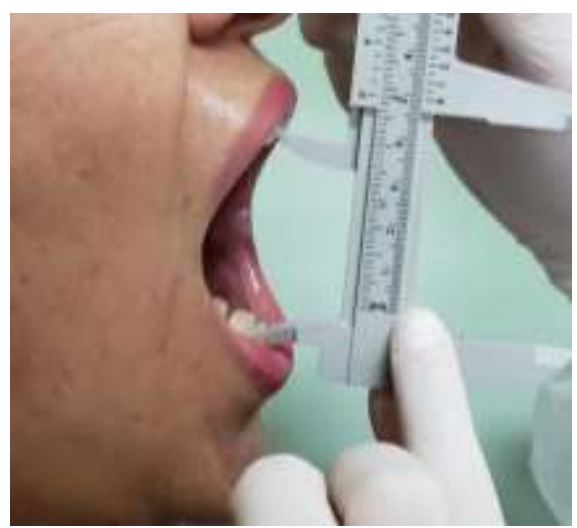

Figura 19: Abertura bucal final, com 46mm.

DISCUSSÃO

Acredita-se que pelo menos $80 \%$ da população tenha algum tipo de sinal e/ou das disfunções craniocervicomandibulares, porém a assertividade neste diagnóstico é limitada. Para este fim é importante a história da paciente, anamnese, exame físico, palpação dos músculos mastigatórios e cervicais, além do exame de imagem para o fechamento do diagnóstico.

Além do mais, a identificação no exame físico, de pontos-gatilho nesta musculatura mastigatória e cervical bilateral, mas principalemente do lado esquerdo, a restrição da abertura bucal, a deflexão mandibular para o lado esquerdo, dor de cabeça, zumbido em orelha, estalido, vertigem, pontadas no peito, assimetria postural, deslocamento da cabeça para anterior e levemente para a esquerda foram os sinais apresentados nesse caso que levaram ao diagnóstico correto. Isso tudo como consequência dos hábitos parafuncionais e má postura durante a sua função, além de eventuais estresses, que decorreram a uma disfunção muscular cervical e mastigatória, comprometimento do sistema manducatório e as alterações vestibulococleares. Essas últimas que levaram à paciente procurar assistência com o otorrinolaringologista, e após o profissional não ter encontrado nenhuma alteração infecciosa ou inflamatória, a encaminhou para o Serviço de Estomatologia da Universidade do Estado do Amazonas (UEA), onde encontrou a explicação de todas as alterações bucais (estalido, deslocamento mandibular), e também, das suas alterações vestibulares e cocleares.

Os sinais e sintomas relatados, as infusões de lidocaína $2 \%$ que foram feitas, utilizada também pelo autor Okeson ${ }^{11}$, a anamnese, a palpação dos músculos mastigatórios e cervicais, a avaliação física e o exame complementar de ressonância magnética foram importantes e decisivos para o correto diagnóstico final, 0 que nos possibilitou promover um tratamento eficaz para a disfunção craniocervicomandibular, as alterações vestibulococleares, os estalidos e a assimetria postural, tendo uma melhora significativa no quadro de dores da paciente em apenas uma semana, progressão positiva dos outros sinais com o tratamento proposto - uso da placa miorrelaxante, os exercícios de fisioterapia e a crioterapia e termoterapia. Esse tratamento, preconizado por Okeson ${ }^{7}$, para que haja uma promoção de oxigenação na musculatura, liberação do ácido lático acumulado, e assim, liberando os focos hipersensíveis que causam as dores referidas, tirando aquela musculatura da hiperatividade e reestabelecendo a propiocepção neuromuscular, explicando a reorganização da musculatura progressivamente, a devolução da amplitude bucal, resolução do desvio mandibular, além da melhora do zumbido, sensação de plenitude auricular, a vertigem e as dores de cabeça, 
comprovando a efetividade do tratamento.

Não houve no trabalho avaliação oclusal ou dentária, discordando de alguns embasamentos na literatura, como Madeira ${ }^{10}$, que a alterações oclusais causam ou tratam as disfunções temporomandibulares.

Além disso, é de extrema importância no tratamento das DCCM's que seja feito a avaliação psicológica do paciente e seja feita uma boa anamnese para saber como é a rotina dele, já que existem casos de dores e disfunções que são produtos de alteração no eixo hipotálamo-hipófise-adrenal, para que cada caso seja individualizado e que tenha 0 atendimento multidisciplinar necessário ${ }^{2,11}$. No caso em discussão, os episódios de estresse da paciente eram eventuais, então não foi necessário o encaminhamento ao psicólogo ou outra terapia, apenas foi conversado que o estresse e a ansiedade poderiam levar ao agravamento do caso.

É importante esclarecer que o tratamento dessas condições não consiste em somente instalar a placa miorelaxante. É preciso que o paciente seja orientado e fique ciente da sua condição, além disso, é necessário o acompanhamento do paciente semanalmente, principlamente no início do tratamento, para que seja feito os ajustes na placa ou ver a progressão do quadro dele com os exercícios. Dessa forma, é importante que as placas miorrelaxantes não sejam a única opção de tratamento para o paciente disfuncional, porque pode acabar decepcionando tanto o profissional quanto paciente, pela falta da resolução ou melhora da condição ${ }^{12}$. O que, nesse caso, foi bem planejado o tratamento da paciente, houve acompanhamento, ajustes tanto na placa como na fisioterapia, dando assim, um bom resultado e melhora do quadro.

É necessário conversar e explicar ao paciente o quanto a participação, a dedicação e a colaboração dele durante todo o tratamento é importante para a progressão positiva do quadro, porque assim ele mantém a rotina diária dos exercícios de fisioterapia, o uso da placa miorrelaxante, e sua própria consciência para controle psicológico. Por isso, nesse caso, o resultado foi tão rápido, positivo e efetivo. $\mathrm{E}$ em 1 ano e 11 meses de acompanhamento, não houve recidiva do caso, mas a paciente continuará em contato com a equipe para informá-los, caso haja.

CONCLUSÃO

Diante do resultado favorável obtido nesse caso clínico, as técnicas utilizadas, por serem não invasivas e reversíveis, sugere-se utilização das mesmas pelo clínico como alternativa segura e efetiva para o tratamento das disfunções craniocervicomandibulares.

Conclui-se também, que a postura incorreta adotada durante a função diária do paciente e hábitos parafuncionais são um fator desencadeante das disfunções craniocervicomandibulares.

A chave para o sucesso no tratamento foi a correta abordagem, a boa anamnese, os exames físicos e complementares para o correto diagnóstico da condição, associado à individualização do plano de tratamento e principalmente, a colaboração e dedicação da paciente.

\section{REFERENCIAS}

1. Cauás M, Alves IF, Tenório K, Filho JB, Guerra $\mathrm{CM}$. Incidências de hábitos parafuncionais e posturais em pacientes portadores de disfunção da articulação craniomandibular. [pesquisa científica]. Rev cir traumatol bucomaxilo-fac. 2004;4(2):121-29.

2. Godinho GV, Cabral LN. Disfunção craniocervicomandibular e alterações vestibulococleares: revisão de literatura. Arch Health Invest. 2019;8(8):405-12.

3. Urban, VM, Neppelenbroek KH, Pavan S; Júnior FGPA, Jorge $\mathrm{JH}$, Almilhatti $\mathrm{HJ}$. Associação entre otalgia, zumbido, vertigem e hipoacusia com desordens temporomandibulares.RGO;2009;57(1):107-15.

4. Wiesenfeld-Hallin Z. Sex differencs in pain perception. Gent Med. 2005;2 (3):137-45.

5. Fillingim RB, King CD, Ribeiro- Dasilva MC, Rahim-Willians B, Riley JL. Sex, gender, and pain: a review of recent clinical and experimental findings. J Pain. 2009;10(5): 447-85.

6. Sarlani E, Garett PH, Grace EG, Greenspan JD. Temporal summation of pain characterizes women but not men with temporomandibular disorders. J Orofac Pain. 2007;21(4):309-17.

7. Okeson JP. Tratamento das desordens temporomandibulares. In: Tratamento das Desordens Temporomandibulares e Oclusão. 6a Ed. São Paulo: Elsevier; 2008.

8. Spillere A, Rosas RF. Tratamento fisioterapêutico na disfunção da articulação temporomandibular (ATM): um estudo de caso. Rev Bras Fisioter, 2002;3(2).

9. Naliboff BD, Berman S, Chang L, Derbyshire SW, Suyenobu B, Vogt BA et al. Sex-related differencs in IBS patients: central processing of visceral stimuli. Gastroenterol. 2003; 124(7):1738-47.

10. Madeira MC, Rizzolo RJ, Anatomia da face Bases Anatomofuncionais para a prática Odontológica. 8. ed. São Paulo: Sarvier; 2012. 
11. Okeson, JP. Dores Bucofaciais de Bell. 6. ed. São Paulo: Quintessence; 2006.

12. Martins BLA, Braga DRLM, Cabral LN. Disfunção massetérica e sialoadenite de refluxo: relato de caso. Arch Health Invest. 2019;8(1):43-7.

\section{CONFLITO DE INTERESSES}

Os autores declaram não haver conflitos de interesse

AUTOR PARA CORRESPONDÊNCIA

Lohanna Karoline Rodrigues Rossete

Avenida Coronel Teixeira, 6225

Condomínio Reserva Inglesa, apto 1802, torre 3 London, Ponta Negra

69037-000 Manaus - AM, Brasil

Telefone: +55 (92) 98408-1630

Email: lohanna.rossete@gmail.com

Submetido em 23/04/2020

Aceito em 23/10/2020 